\title{
A vida precisa de biomas vivos
}

Recebido: 15/10/2016. Aprovado: 31/10/2016.

\author{
Sara Poletto* \\ Ivo Poletto**
}

Resumo: A Campanha da Fraternidade de 2017 é uma oportunidade especial: a de maravilhar-se com os biomas, os berços para a vida que a Mãe Terra construiu no longo processo da Criação, especialmente em nosso país. Insistindo na sua tese de que "a vida precisa de biomas vivos", o autor a desenvolve em quatro pontos: $1^{\circ}$, abrir o coração para a oportunidade; $2^{\circ}$, conscientizar-se de que 0 começo não é o da espécie humana; $3^{\circ}$, aprofundar a relação entre os biomas e a vida; $4^{\circ}$, meios de recuperar a beleza natural dos biomas; $5^{\circ}$, a convivência com os biomas e a mudança climática. Concluindo, o autor convida a reaprender a viver com mais simplicidade, sendo menos pesados para a Mãe Terra. Para que cada bioma recupere seu equilíbrio favorável à vida.

Palavras-chave: Campanha da Fraternidade. Biomas. Mudança climática. Sustentabilidade.

Abstract: The 2017 Fraternity Campaign is a unique opportunity of paying attention to the biomes, the birthplace for the life that Mother Earth engendered in the long process of Creation, especially in our country. Insisting in his thesis that "life needs living biomes", the author presents it in 5 points: first, opening the heart for this opportunity; 2nd, becoming aware that the beginning is not of the human species; 3rd, going deep into the relation between biomes and life; 4th, means of recovering the natural beauty of the biomes; 5 th, the biomes and climatic change. Finally, he invites learning how to live more simply, being less toilsome to Mother Earth. In this way, each bioma will recover its balance favorable to life.

Keywords: Fraternity Campaign. Biomes. Climatic change. Sustainability.

* Mestre em Antropologia pela UnB. Coordenadora de Planejamento Estratégico e Metodologia do Projeto Pesca Sustentável na Costa Amazônica, Setor de Ciências Naturais da UNESCO.

** Assessor Nacional do Fórum Mudanças Climáticas e Justiça Social. 


\section{Abrir o coração para a oportunidade}

A CF 2017 é uma hora da graça especial: a de maravilhar-se com os biomas, os berços para a vida que a Mãe Terra construiu no longo processo de Criação. Para quem vive na região central do país, por exemplo, a oportunidade de dar-se conta de que o Cerrado é um dos biomas mais antigos do planeta Terra, e que, por isso, precisa ser cuidado com carinho especial, já que, se for destruído, dificilmente a Terra conseguirá recriá-lo.

Mesmo com idades diferentes, a Mata Atlântica, com a Zona Costeira, a Caatinga semiárida, a Amazônia, o Pampa e o Pantanal são outros berços de vida únicos, que não se repetem. ${ }^{1}$ Como cada ser é único, diferente dos demais, e portador, então, de uma mensagem de quem o criou, da mesma forma cada bioma tem características próprias, é constituído por um conjunto de relações e energias que torna possível a existência de seres vivos diferentes dos que vivem em outros biomas. $\mathrm{E}$ a própria vida humana, por mais que possa intervir e mudar os ambientes em que se estabelece, cria formas culturais marcadas pelas condições oferecidas pela Terra em cada bioma.

A presença de seres humanos em nosso país ultrapassa doze mil anos, e há sinais que indicam que esta história pode ser bem mais longa, com mais de quarenta mil anos. É claro que, dadas as suas características, os homens e mulheres interferiram nos biomas criados pela Terra. Durante a maior parte desta história, as mudanças introduzidas tiveram como objetivo a sobrevivência e reprodução da espécie, e por isso, não significaram uma agressão ao ambiente vital. Mas, ao prestar atenção à realidade atual da vida de cada bioma brasileiro, pode-se dizer que as pessoas humanas modificaram o ambiente que encontraram apenas em função de sua própria existência?²

Se retomarmos a história anterior à invasão europeia no século XVI, a resposta é positiva: os mais de dois mil povos indígenas existentes

1 Persiste o debate sobre quantos são os biomas existentes no Brasil: 6 ou 7? No site <http://7a12.ibge.gov.br/vamos-conhecer-o-brasil/nosso-territorio/biomas.html> está publicado um mapa com 7 biomas, mas há outras publicações que consideram a Zona Costeira, ou os Biomas Costeiros, como parte do bioma Mata Atlântica. O importante é estar atentos às particularidades dos ecossistemas existentes na longa costa brasileira.

2 BARBOSA, Altair Sales. Andarilhos da claridade: Os primeiros habitantes do Cerrado. Goiânia: Ed. UCG, 2002. São instigantes as informações deste destemido pesquisador e servem de referência para a reflexão que segue. 
nesse território antes de 1.500 vivenciaram relações de convivência e de harmonia com a natureza de cada bioma. A pesquisa mostra que, em 12 mil anos, alteraram, por exemplo, apenas $12 \%$ do território do Cerrado.

Depois de 1.500, contudo, a resposta é negativa: as relações com a natureza mudaram e avançaram na direção da exploração comercial e da sua transformação em recursos de processos industriais capitalistas. No lugar do respeito e cuidado com a vida existente e com a própria vida humana em cada ambiente vital, foi avançando o predomínio de diferentes formas de riqueza, ora centradas no comércio internacional de bens naturais, ora centradas na compra e exploração de escravos indígenas ou africanos, até chegar à propriedade privada de terra e à propriedade dos meios de produção industrial, do tempo de trabalho dos trabalhadores contratados através de contratos monetários, e, finalmente, da mais valia contida nos produtos do processo de trabalho transformada em lucros. Ao contrário dos dados oficiais, o pesquisador Altair Barbosa afirma que a área preservada do Cerrado original não passa de $15 \%$.

A oportunidade que Deus nos concede nesta CF não é apenas a redescoberta, a contemplação gratuita e agradecida das maravilhas criadas pela Terra com a presença do Espírito de Deus; é igualmente oportunidade para verificar como estão os biomas hoje, depois das modificações introduzidas por ações humanas. E para enfrentar as perguntas que o Criador e a Mãe Terra nos apresentam: "Por que e para que os seres humanos modificaram de forma tão agressiva os biomas? O que vocês farão para recriar os berços de vida que graciosamente foram oferecidos por nós a todos os seres vivos e a vocês?"

Este artigo tem como fontes próximas os sábios depoimentos de representantes dos povos e comunidades tradicionais dos diferentes biomas, bem como as exposições de pesquisadores acadêmicos e as reflexões dos participantes de seis seminários promovidos pelo Fórum Mudanças Climáticas e Justiça Social nas grandes regiões do país em 2016, atualizando os levantamentos e reflexões críticas realizadas sete anos antes nessas mesmas regiões.

\section{O começo não é da espécie humana}

Temos o hábito de pensar a realidade a partir de nós, a espécie humana. De modo particular no período histórico da modernidade, o antropocentrismo se tornou absoluto, e tomou a forma de androcentrismo, 
isto é, a montagem de sociedades assentadas sobre a dominação dos homens sobre as mulheres. A emergência da individualidade foi certamente um dos avanços que a modernidade trouxe para a humanidade, mas na medida em que o processo de afirmação da liberdade foi submetido e até substituído pelo predomínio da livre iniciativa capitalista, as pessoas passaram a ser educadas para o uso do individualismo. E é correto falar em "uso", porque a livre iniciativa capitalista tem como um de seus fundamentos a concorrência entre os que têm poder de abrir iniciativas com potencial de reproduzir o capital aplicado. O egoísmo, isto é, a prática individualista que visa satisfazer os desejos do investidor, deixa de ser algo negativo, ameaçador e destruidor das comunidades humanas, e passa a ser promovido como valor, como virtude, como dinâmica capaz de gerar um progresso constante.

Essa absolutização da livre iniciativa de quem tem poder de investir capital introduziu na história humana profundas contradições, das quais destaco apena duas. A primeira é a que relaciona e opõe capital e trabalho. A capacidade humana de transformar bens da natureza em utilidades para manter e reproduzir a vida foi reduzida a um tempo de trabalho comprado pelo capitalista para produzir as mercadorias que garantem a acumulação de seus lucros. O trabalhador foi alienado de sua livre capacidade de produzir valor, e passou a ser obrigado a realizar o que interessa ao senhor da livre iniciativa em troca do dinheiro com que deve manter e reproduzir a sua vida e a de sua família.

A segunda contradição foi estabelecida entre o desejo de um crescimento econômico sem fim, com espoliação e transformação de bens naturais, e a finitude e limites da natureza do planeta Terra. Nesse confronto, a livre iniciativa capitalista está fadada à derrota. Ou ela não sobreviverá aos eventos climáticos cada vez mais extremos, ou ela deixa de existir e é substituída por outros modos de produção, centrados e a serviço das condições possíveis de vida neste Planeta. O grande desafio provocado pelo desenvolvimento concreto dessa contradição é o aprofundamento do sofrimento e da falta de perspectivas da maioria dos seres humanos, afetados pela exploração capitalista de seu trabalho e da natureza.

Essa breve caracterização dessas contradições da modernidade é necessária para dar-nos conta de como pode ser diferente a vida humana quando pensada a partir dos biomas, e não a partir dos interesses dos 
indivíduos humanos individualistas, de modo especial quando esses interesses tomam a forma de reprodução constante e ampliada do capital.

O ponto de partida, nesse caso, é dado por cada um dos berços de vida constituídos no longo processo de criação da Terra que os seres humanos encontraram quando iniciaram sua aventura por aqui. Em outras palavras, trata-se de reconhecer que o começo, muito antes da emergência da livre iniciativa capitalista, é da Terra. ${ }^{3}$ Foi ela - e com ela, o Criador que a dinamizou - quem criou os biomas em que os seres humanos vivem. Todos os seres que constituem a biodiversidade de cada bioma, e fazem dele um berço de vida único, foram sendo gerados no longo processo de criação da Terra até tomarem a forma que os seres humanos encontraram ao entrar nesta história de geração apaixonada de vida.

Isso nos leva a colocar em questão a pretensão do ser humano de autodefinir-se o centro da vida, e de pretender ser portador exclusivo de direitos, ao ponto de reduzir tudo que constitui a vitalidade de cada bioma em meros recursos naturais, a serem apropriados em função dos interesses individuais dos que têm poder de capital. E a afirmar e justificar em leis e constituições que a razão humana é capaz e por isso, pode e deve submeter a natureza em função de um processo de produção de mercadorias e lucros sem fim, e defender essa apropriação individual como algo sagrado, mesmo se isso gera e aprofunda as desigualdades entre os próprios seres humanos, provocando até mortes por fome ou por defesa da propriedade, e gera elevação da temperatura do Planeta e agrava as mudanças climáticas e seus efeitos sobre todos os seres vivos, de modo especial sobre os pobres. ${ }^{4}$

\section{A realidade da relação entre os biomas e a vida}

As sociedades ocidentais tiveram um olhar enviesado da natureza: ao tornar-se a perspectiva julgada natural, a mediação da propriedade privada, definida nas constituições e leis como base para a livre iniciativa,

3 O debate sobre os direitos da Terra se aprofundou a partir da decisão dos Constituintes que elaboraram a CONSTITUIÇÃO POLÍTICA DEL ECUADOR, e dos cidadão que a aprovaram em plebiscito, de assegurarem, no Capítulo Séptimo, Los derechos de la naturaleza. Ver em: <http://www.produccion.gob.ec/wp-content/uploads/downloads/2012/07/Normas_Constitucionales.pdf>.

4 SANTOS, Boaventura de Sousa. A Crítica da razão indolente - Contra o desperdício da experiência. São Paulo: Cortez editora, 2001. Este autor é referência para a análise crítica da modernidade capitalista. 
foi reduzindo a Terra a um recurso que pode ser comprado e vendido, negociado no mercado de terras, fonte de especulação. E o processo histórico de construção dessa forma de relação com a Terra contou com o sucesso da proposta de dessacralização da natureza. A hegemonia da visão e da prática capitalista de apropriação privada, que dá direito ao proprietário de fazer o que quiser, foi construída sobre a negação de sentido das culturas fundadas sobre o valor sagrado do território destinado pelo Criador a cada povo para nele viver. A Terra é Pachamama, a Mãe da vida, e tudo que existe nela é sagrado, tem espírito e deve ser respeitado. O ser humano é parte da Pachamama, só pode viver nela e com suas energias. Por isso, ela não pode ser dividida em definitivo, vendida, comprada.

Foi preciso destruir essas formas "atrasadas" de relacionar com a Terra. A possibilidade do progresso capitalista precisava fazer que ela fosse apenas "natureza", isto é, um conjunto de "coisas", um tipo de depósito de recursos a serem apropriados para desenvolver o processo de produção de mercadorias e geração de lucros. Foi dessa forma que a agricultura capitalista reduziu os solos, subsolos, água, atmosfera, junto com as máquinas, as sementes, os produtos químicos, os grãos, a carne e todos os demais produtos agrícolas a insumos da agroindústria transnacional. Tudo é mercadoria, a começar pelo espaço de produção, a propriedade privada.

Com esses "avanços tecnológicos", faz algum sentido levar em conta as características de cada bioma? De forma alguma, respondem os técnicos e políticos do sistema hegemônico, já que todo solo pode ser "corrigido" e adequado à produção que se deseja desenvolver. E se por acaso faltarem "recursos naturais", como a água, por exemplo, nada impede que ela seja extraída dos lençóis e aquíferos através de poços profundos. A referência absoluta é a produção de lucros em todo o processo de agroindustrialização. De certa forma, esse processo usa ao extremo os recursos naturais disponíveis sem que seu uso e sua degradação constem no preço dos produtos, e os substitui e/ou complementa, quando necessário, com produtos industriais tecnologicamente elaborados por grandes laboratórios, agora tudo devidamente pago pelos consumidores finais.

O império absoluto do lucro, defendido nas leis como direito da livre iniciativa e justificado como motor do crescimento econômico contínuo e, de forma mecânica, gerador de bem-estar social através do aumento do trabalho assalariado e do consumismo, gera e justifica uma 
profunda irresponsabilidade socioambiental. Um exemplo: nenhum proprietário se considera responsável pelo desmatamento de algo próximo a 93\% da Mata Atlântica; ele apenas desmatou a sua propriedade, e o fez como condição para gerar progresso econômico com diferentes tipos de produtos. Se a soma das práticas individuais provocou o desequilíbrio dos múltiplos e complexos fatores que constituem o bioma, e se isso se expressa na crise da água doce para beber e para outros usos, até mesmo para irrigar a produção agropecuária e florestal, isso é um "problema global" e deve ser enfrentado com investimentos públicos, ou com apoios públicos para novos negócios privados.

É importante acrescentar mais algumas práticas de relações com os biomas: a vida urbana em grandes cidades, e as indústrias, igualmente construídas nos espaços urbanos. Uma vez mais, o império absoluto do lucro por parte dos que detêm propriedade e capital faz com que a contaminação e deterioração dos córregos e rios, bem como do solo, subsolo e atmosfera seja um problema global, e não de cada empresário, e por isso, seu enfrentamento é cobrado do poder público, exigindo investimentos públicos ou oportunidade de novos negócios privados com recursos públicos. Da mesma forma, cada pessoa, cada família, não se sente responsável pelo total do lixo e do esgoto, nem pelas condições ambientais de seu bairro, e todos cobram do poder público, que certamente tem grande responsabilidade tanto pela falta de planejamento das condições de vida urbana como pela falta de educação socioambiental. Cabe a ele, sim, a mobilização da população para que os cuidados com o ambiente da vida sejam missão de todas as pessoas, das empresas e do governo democraticamente instituído.

De toda forma, o que resta do bioma em que a cidade foi incrustrada? Como repensar a cidade como parte do bioma em que está?

Tudo somado, como estão os biomas brasileiros?

Todos estão radical e irresponsavelmente modificados, num processo iniciado com a chegada dos europeus no século XVI, mas que foi acelerado a partir dos anos 50 do século passado. A Mata Atlântica está irreconhecível: só restam 7\% da cobertura vegetal criada pela Terra, e não se tem informações seguras sobre a quantidade de espécies de seres vivos que deixaram de existir. Entre estes seres vivos, vale destacar os povos denominados indígenas, quase todos apenas lembrados como nomes de ruas das grandes cidades, especialmente São Paulo. E os ecossistemas próximos ao Atlântico - que para muitos constituem um bioma, 
denominado Zona Costeira - continuam sendo afetados pela presença de novas cidades e empreendimentos ligados ao turismo, aos portos, às indústrias de mineração, e mais recentemente, à criação industrial de camarões, às grandes empresas de produção da mercadoria energia elétrica com o uso dos ventos.

$\mathrm{Na}$ ameaçadora crise de água de 2015 na região Sudeste, a destruição do bioma Mata Atlântica se fez sentir. Antônio Donato Nobre, do INPE, comparou-a a uma "poupança", a ser usada quando, por motivo de desemprego ou doença, a renda normal deixou de entrar na conta. De fato, a umidade necessária para haver chuvas nesta Região vem normalmente do bioma Amazônia, de parte do rio aéreo formado nele e trazido pelos ventos desviados pela Cordilheira do Andes. Como a Amazônia já está desequilibrada, de modo especial pelo desmatamento de mais $20 \%$ de sua área, e diminuem tanto o rio aéreo como os ventos, torna-se previsível o agravamento de secas no Sudeste. Nessa hora, a Mata Atlântica, se ainda existisse plenamente, se tornaria a "poupança" de umidade e água, diminuindo a dramaticidade da situação. ${ }^{5}$

Como se percebe, os biomas são berços únicos de vida, diferentes dos demais, mas não existem isoladamente: eles são interligados por espaços de transição de um para o outro, e se interligam pelos ventos, umidade e gases da atmosfera, bem como pelas artérias e veias em que correm as águas. Isso fica ainda mais claro quando prestamos atenção às relações entre o Cerrado, bioma do planalto central do Brasil, e os demais biomas. É da natureza original, do DNA, do Cerrado, ser um tipo de "caixa d'água" elevada, abastecida pelas fortes precipitações do "tempo das chuvas" - já que seu clima era dividido em "tempo de chuva", que começava em setembro e se estendia até final de março/início de abril, e "tempo sem chuva" -, que penetravam no seu solo parecido com uma "esponja", e garantiam água abundante para o próprio bioma e para os vizinhos. Ele serve, a partir da nascente das "aguas espraiadas" do Distrito Federal e de inúmeros outros olhos d'água, mais de $80 \%$ das águas do São Francisco, longo e vital rio da Caatinga; serve mais de $80 \%$ das águas do Pantanal, o bioma em que explode vida e beleza; serve água para a Amazônia, através dos rios Tocantins e Araguaia, dos rios que formam o vale do Tapajós e tantos outros; serve água para o

5 Ver NOBRE, Antônio Donato. O futuro climático da Amazônia. Texto publicado pela Articulação Regional Amazônica (ARA). Disponível em: <http://www.cest.inpe.br/wp-content/uploads/2014/10/Futuro-Climatico-da-Amazonia.pdf>. 
que resta da Mata Atlântica e para o bioma Pampa, através dos córregos e rios que se juntam no Rio Grande, no Paraná, e deságuam no estuário do Prata, já na Argentina...

Por sua vez, o Cerrado depende quase inteiramente da umidade que chega da Amazônia para retomar o tempo das chuvas...

Tendo tudo isso presente, o que já está acontecendo, com o avanço frenético do desmatamento e da morte das raízes da vegetação do Cerrado em função do projeto japonês de "desenvolvimento do Cerrado" com produção de grãos, carne e etanol para o mercado mundial? ${ }^{6}$

Diminuição do "tempo de chuva" - no de 2015 para 2016 houve menos da metade da quantidade média de chuvas na região; maior uso de poços para abastecimento e irrigação, provocando diminuição das águas dos aquíferos alimentados pelo Cerrado, e por isso, muitas fontes secaram, e com elas, também córregos, com diminuição acentuada nos rios permanentes; ameaças de falta de água, sentidas até mesmo em Brasília, DF; perda de colheitas por seca e aumento de incêndios... Trata-se de uma sequência que, se for transformada em permanente, se tornará um círculo vicioso rumo à desertificação.

E o que acontecerá com a Caatinga, um bioma semiárido, ainda ameaçado com o avanço do desmatamento, com pecuária, com plantações de eucaliptos, com produção de frutas exóticas para exportação, com mineração descontrolada? Mesmo desejando intensamente que as previsões não se confirmem, a região sofrerá com o aumento significativo da temperatura, provocando mais instabilidade das chuvas, aumentando as áreas desertificadas. Completando a falta de cuidado, até mesmo a produção de energia eólica por grandes empresas está sendo mais uma atividade agressiva ao meio ambiente, de modo particular na zona costeira, e fonte de novos conflitos socioambientais.

\section{Como recuperar a riqueza natural dos biomas?}

Há um ponto de partida, uma condição sem a qual nada de novo será possível: que os biomas sejam reconhecidos com seriedade, para

6 Vale lembrar que o nome inicial deste projeto foi "Projeto JICA", o órgão oficial de apoio ao desenvolvimento do Japão, interessado em sua segurança de grãos, e que implementou, com a ditadura brasileira, o PRODECER - Programa de Desenvolvimento do Cerrado, que continua até hoje, no denominado Projeto MATOPIBA. 
corrigir o que se fez sem levar em conta suas características, e para que as relações humanas com cada um deles sejam redefinidas a partir do princípio estratégico da convivência. Da parte dos seres humanos, esta deve ser uma escolha e uma decisão, e certamente terá uma resposta entusiasta da Terra e da comunidade dos seres de cada bioma.

Os biomas do Cerrado e da Caatinga nem mesmo são reconhecidos como patrimônios nacionais, como proposto ao Congresso Nacional ainda em 1995. ${ }^{7}$ Esse atraso se deve ao interesse do agronegócio de mantê-los como áreas livres para exploração agropecuária. De forma irresponsável, líderes desse setor da oligarquia afirmam que a Amazônia, sim, mereceria este título e deve ser preservada, mas não o Cerrado e a Caatinga, que têm uma cobertura vegetal "que não vale nada". Na verdade, arrasaram o Cerrado, aumentaram a destruição da vegetação da Caatinga e, dessa forma, avançaram também sobre a Amazônia, sempre em nome do absoluto do crescimento econômico.

Nesse quadro, uma das mobilizações da CF 2017 pode ser exatamente esta: a de exigir que estes dois biomas sejam reconhecidos como patrimônio nacional. Mas isso só acontecerá quando as pessoas tomarem consciência da importância vital desses dois biomas, um por ser o berço das águas e outro para evitar que o Semiárido vire deserto e agrave as condições de vida de mais de 30 milhões de pessoas. E há a campanha SEM CERRADO NÃO HÁ VIDA, que só será vitoriosa se for apoiada em todo o território nacional. ${ }^{8}$

Em relação ao bioma Caatinga, a Articulação pelo Semiárido Brasileiro (ASA) tem certamente o mérito de ter evitado o avanço de práticas destrutivas, e o fez com a promoção de práticas novas de relações dos seres humanos com a natureza. Seu objetivo estratégico é a promoção da "convivência com o Semiárido". Isto é, o aprendizado de que, num semiárido, é inútil teimar em promover "políticas de combate à seca", pelo simples motivo de que a existência de períodos mais ou menos longos de seca é uma das características das regiões semiáridas. A "convivência", por outro lado, não é aceitar passivamente a seca e seus efeitos na vida das pessoas e da natureza. É, sim, usar a inteligência para dar-se conta de que há chuvas na região, mesmo se mal distribuídas no

$7 \quad$ PEC n 115, de 1995, que inclui o Cerrado e a Caatinga na relação dos biomas considerados patrimônio nacional.

8 Buscar contato em: <semcerrado.org.br>. 
tempo e no espaço. Conviver é então criar condições para captar as águas das chuvas para dispor delas nos períodos de estiagem.

É por isso que, mesmo não sendo ainda reconhecidas como a única política adequada para a região, as iniciativas das comunidades sertanejas, animadas pelas mais de 800 entidades articuladas pela ASA, já fizeram a diferença. Mais de um milhão de famílias conta com sua cisterna caseira, e isso significa água saudável, e muitas delas já contam com a segunda cisterna, maior e destinada a garantir a produção do alimento básico. Com isso, mesmo com a seca atual, que já chega a perto de seis anos de duração, poucas famílias migraram e não foram necessários os anteriormente tradicionais saques de alimentos nos armazéns.

É essencial deixar claro que o "guardar água" é o segredo da convivência, mas não é tudo. Ela se torna de fato convivência quando as pessoas e comunidades conhecem a natureza deste semiárido, e por isso, junto com as cisternas, mudam sua forma de cultivar a terra, retomam as sementes e os animais próprios da região, desenvolvem uma educação contextualizada, em que o avanço nos conhecimentos se faz junto com a consciência do que se deve fazer para viver neste bioma. É maravilhoso ver a paixão com que se reaprende a produzir em sistemas agroflorestais, melhorando a qualidade dos produtos com menos uso de água e ajudando o solo a guardar umidade - e, nesse sentido, combatendo os efeitos dos naturais tempos de seca. ${ }^{9}$

Esse é, sem dúvida, o caminho geral de recuperação da vida nas diferentes regiões: a promoção de práticas de convivência com as características de cada bioma. O caminho é o mesmo, mas as práticas são necessariamente diferentes. Conviver com a Amazônia, por exemplo, é encontrar formas de produzir o que se necessita para viver com qualidade sem destruir a floresta que ainda está em pé. É também relacionar-se com as águas sem contaminá-las, sem acabar com as espécies de seres vivos existentes nos rios, lagos, igarapés. Em termos gerais, é ser um dos seres deste bioma, que convive com os demais, que se alimenta com o que a natureza da região produz.

Conviver com a Amazônia é também dar-se conta de que ações humanas já modificaram muito o que a Terra criou. Mudanças introduzidas pela forma de vida dos empresários e pessoas que chegaram, em diferentes momentos da história, mas especialmente a partir dos anos

9 Buscar mais informações no site: <asabrasil.org.br>. 
setenta do século XX, com a pretensão de levar o "desenvolvimento econômico" a esta região atrasada. Uma forma de vida centrada na implantação de grandes fazendas, de grandes mineradoras, de vias de escoamento para os portos localizados em grandes cidades, cercados de indústrias eletrointensivas, como as de alumínio, de hidrelétricas, para suprir a necessidade dessas empresas. E para viabilizar a importação de máquinas e outros produtos para esses empreendimentos, a montagem da Zona Franca de Manaus.

A prática de convivência tem como desafio ir demonstrando que o caminho do pretenso desenvolvimento econômico acelerado - na linha do "programa de aceleração do crescimento", PAC - já está levando a Amazônia aos desequilíbrios existentes nos demais biomas, e que, a teimosia de continuar nesse modelo levará à destruição da imensa e riquíssima sociobiodiversidade deste bioma.

Assim como na Caatinga semiárida e na Amazônia, a elaboração de propostas de formas alternativas de viver e conviver com a natureza é uma necessidade urgente em todos os biomas do Brasil - e do mundo, com certeza. Em nosso caso, esse desafio se faz presente e precisa de maior empenho nos biomas Cerrado, Pantanal, Pampa, Mata Atlântica e a Zona Costeira. E o ponto de partida, tanto para iniciativas locais concretas como para a elaboração de projetos mais amplos de convivência, está na resposta a esta pergunta: em que e como estão afetados ou até negados os direitos da Mãe Terra? Isso pode e deve levar a práticas e projetos de recuperação das coberturas vegetais próprias de cada bioma, de recuperação das fontes, dos córregos, rios e lagos com suas matas ciliares, de recuperação da qualidade da atmosfera, de recuperação da vitalidade dos solos, condição para a reeducação para alimentar-se com fontes de alimentação próprias de cada bioma. Estas práticas podem abrir caminhos para a recuperação de espécies de seres vivos típicos, reorganizando as comunidades de vida de que o ser humano é parte.

Vale perguntar-nos: nossas cidades foram pensadas e planejadas para serem espaços de vida coletiva adequados ao bioma em que estão existindo? A resposta é certamente negativa. Muito raramente nasceram de um projeto. Brasília, Belo Horizonte, Goiânia, Palmas, são cidades planejadas para serem capitais, de estados e do país, e por isso mesmo, o planejado existe em função da sua finalidade central: a administração política. A explosão populacional de todas elas se deu de forma desorganizada, a partir de ocupações em busca de um espaço para erguer um 
barraco, em volta de empresas em busca de oportunidades de trabalho. Tanto a parte planejada como a construída a partir de iniciativas espontâneas tem pouco ou nada a ver com as características do bioma: com atenção, por exemplo, ao regime de chuvas e de águas, com a temperatura e demais elementos do clima...

Por isso, reorganizar a vida humana vivendo e convivendo com o bioma exige e depende de uma visão holística e sistêmica da realidade: como tudo está interligado, tudo deve ser planejado e executado sabendo em que e como cada prática interfere em todos os fatores que tornaram possível e que mantêm a possibilidade da vida em cada bioma.

É com essa visão e com esse princípio ao mesmo tempo científico e ético que se deve rever e recriar a agricultura, a criação de animais, as vilas, as cidades, a mobilidade urbana e rural, a produção e uso de energia com escolha das fontes menos poluentes existentes, extração ou não de minerais e de fontes fósseis de energia... Trata-se, então, de uma mudança profunda do estilo de vida dominante, promotor do consumismo, que mantém o produtivismo e generaliza a indiferença e a irresponsabilidade socioambiental. Uma transformação profunda do estilo de vida promovido e adequado a um sistema centrado nos lucros e que, por isso, mata: mata as condições da vida criadas pela Mãe Terra e mata os pobres. ${ }^{10}$

O avanço da reconstrução da vida no Planeta Terra a partir da convivência com cada bioma depende de uma conversão ecológica, como sugere de forma amorosa o Papa Francisco na sua Laudato Si', o Cuidado da Casa Comum. ${ }^{11}$ É preciso redescobrir-se como parte da comunidade de vida, relacionando-se com ela de forma amorosa, libertando-se da tentação de reduzir tudo a recursos naturais que podem ser apropriados, vendidos. É preciso superar a educação para o individualismo, promovida pelo sistema dominante, e reeducar-se para a cooperação, para a economia solidária, para a vida comunitária, para o que caracteriza o ser humano ${ }^{12}$.

10 É assim que o define o Papa Francisco, na Laudato Si' e na sua mensagem ao Encontro do Papa com os Movimentos Populares, realizado em Santa Cruz de la Sierra em julho de 2015, como se pode ver no link <http://pt.radiovaticana.va/news/2015/07/10/ discurso_do_papa_aos_movimentos_populares_(texto_integral)/1157336>.

11 Laudato Si'. Brasília: Cnbb, 2015, p. 127-130.

12 ARRUDA, Marcos. Humanizar o Infra-Humano. Petrópolis: Vozes, 2003, em que o autor contesta a teoria de que o ser humano nasce egoísta e individualista, e demonstra ser ele voltado para o amor. 


\section{A convivência com os biomas e as mudanças climáticas}

O Papa Francisco decidiu publicar a sua encíclica sobre o Cuidado da Casa Comum como parte de sua missão em relação à humanidade, a quem os seguidores de Jesus Cristo oferecem a perspectiva do Reino de Deus. Mas o fez, também, como forma de contribuir com a COP 21, da ONU, que se reuniria alguns meses depois com o desafio de, finalmente, chegar a acordos mundiais para enfrentar as mudanças climáticas provocadas pelo aquecimento global gerado por ações humanas.

O Acordo de Paris, fruto da COP 21, não incorporou as propostas de mudanças profundas sugeridas pelo Papa. Mas, de toda forma, deu um passo importante: reconheceu que as mudanças climáticas são provocadas por ações humanas e se constituem no maior desafio a ser enfrentado solidariamente por toda a humanidade. A partir daí, definiu que a humanidade deve fazer tudo que é capaz para que a temperatura da Terra, que já aumentou praticamente em $1^{\circ} \mathrm{C}$ em relação à existente antes da revolução industrial, fique abaixo de $2^{\circ} \mathrm{C}$, sendo ideal que não ultrapasse $1,5^{\circ} \mathrm{C}$. A partir daí, contudo, acatou a proposta de que cada país definisse voluntariamente o que faria para alcançar este objetivo, e com isso, a possibilidade de que a soma dessas ações não fosse suficiente. $\mathrm{E}$ isso de fato aconteceu: a soma do que os países anunciaram que farão deixará a Terra elevar a temperatura acima $\operatorname{dos} 3^{\circ} \mathrm{C}$.

O Brasil, nesse contexto, anunciou suas Contribuições Nacionalmente Determinadas e Pretendidas (INDC, na sigla em inglês), e com isso procurou ficar bem na foto, até mesmo como um país que age antes dos demais. São ações que deverão contribuir para diminuir a emissão de dióxido de carbono equivalente na atmosfera. As principais estão ligadas à redução do desmatamento, ao reflorestamento, às formas de uso do solo... Mas anunciou que, mesmo incluindo as fontes alternativas na matriz energética, em nada reduzirá sua exploração dos poços petrolíferos do pre-sal, nem modificará sua estratégia de produção de termeletricidade. Em outras palavras, o Brasil é um dos países que anunciou metas pouco ambiciosas, e mesmo assim, metas que podem não ser alcançadas por falta de priorização.

Diante disso, como a CF se propõe criar a consciência de que a vida de qualidade só é possível em biomas preservados em seu equilíbrio originário, será vital que ligue sua mobilização com as lutas contra tudo 
que está elevando a temperatura da Terra e agravando os eventos climáticos extremos, com graves consequências para a vida dos pobres e da Terra. Na verdade, contra tudo que seres humanos fizeram e continuam fazendo para destruir o equilíbrio vital dos berços de vida, os biomas. É fundamental dar-se conta de que as práticas que objetivam ajudar a Terra a recuperar seus biomas são excelentes e necessárias ações para enfrentar o aquecimento do Planeta.

Quem deseja orientar suas opções tendo por base conhecimentos científicos e o bom senso, já sabe o que deve ser feito: junto como o desmatamento zero, recriação de florestas em todas as áreas possíveis; investir em fontes menos poluentes de energia, como o sol e os ventos, de forma descentralizada, para deixar de usar quanto antes o petróleo, o gás e o carvão; mudar o sistema de mobilidade urbana, priorizando o transporte coletivo movido a energia; promover a agroecologia, para ir deixando de lado quanto antes a agricultura química e industrial do agronegócio e da agroindústria; redefinir a política minerária, só admitindo a extração dos minérios absolutamente necessários para a vida, depois de reciclar tudo que é possível...

Em outras palavras, reaprender a viver com mais simplicidade, sendo menos pesados para a Mãe Terra, para que haja o suficiente para todos e, ao mesmo tempo, haja o que a Terra tem direito de recuperar. Para que cada bioma recupere seu equilíbrio favorável à vida, e assim, a vida floresça em todo o Planeta.

Fácil? Não, com certeza. Mas é para alcançar o que parece impossível que existe e continua importante a Campanha da Fraternidade. Afinal, não é esta a mensagem central da Páscoa: a vitória da vida sobre a morte?

\section{Referências Bibliográficas}

ARRUDA, Marcos. Humanizar o Infra-Humano. Petrópolis: Vozes, 2003.

BARBOSA, Altair Sales. Andarilhos da claridade: Os primeiros habitantes do Cerrado. Goiânia: UCG, 2002.

CONSTITUIÇÃO POLÍTICA DEL ECUADOR, Capítulo Séptimo, Los derechos de la naturaleza. Ver em <http://www.produccion.gob.ec/wp-content/uploads/downloads/2012/07/Normas_Constitucionales.pdf $>$. 
FRANCISCO. Encontro com os Movimentos Populares, em Santa Cruz de la Sierra, em julho de 2015. Disponível em: $<$ http://pt.radiovaticana.va/ news/2015/07/10/discurso_do_papa_aos_movimentos_populares_(texto_integral)/1157336>.

FRANCISCO. Encíclica Laudato Si'. Brasília: Cnbb, 2015.

NOBRE, Antônio Donato. O futuro climático da Amazônia. Texto publicado pela Articulação Regional Amazônica (ARA). Disponível em: $<$ http://www.cest.inpe.br/wp-content/uploads/2014/10/Futuro-Climatico-da-Amazonia.pdf $>$.

SANTOS, Boaventura de Sousa. A Crítica da razão indolente: Contra o desperdício da experiência. São Paulo: Cortez editora, 2001.

E-mail dos autores:

sarapoletto@gmail.com ivopoletto@uol.com.br 